\title{
LEUCEMIA MIELOMONOCÍTICA EM UM CÃO
}

\author{
MYELOMONOCYTIC LEUKEMIA IN A DOG
}

\author{
Roselene Ecco $^{1}$ Rafael Fighera $^{2}$ Dominguita Lühers Graça $^{3}$
}

- RELATO DE CASO -

RESUMO

Uma cadela, sem raça definida, de quatro anos apresentou, no período de dois meses, anorexia, emagrecimento progressivo e letargia. Os exames laboratoriais constataram anemia intensa e azotemia e, na ultra-sonografia, observou-se uma massa na região mesogástrica. Após tentativa de tratamento clínico sem resposta, optou-se pela eutanásia. Macroscopicamente, observaram-se acentuada palidez das mucosas, pobre estado nutricional e desidratação. Os linfonodos préesternais estavam aumentados e nos lobos esquerdos do fígado, pâncreas, linfonodos regionais, baço e duodeno havia múltiplos nódulos tumorais branco-amarelados. Microscopicamente, na medula óssea, baço, linfonodos e fígado havia infiltração tumoral por células blásticas com pouco citoplasma, núcleo redondo ou chanfrado, nucléolo proeminente e cromatina fina. Havia, também, moderada quantidade de neutrófilos. A imunoistoquímica da medula óssea utilizando-se o anticorpo NP57 foi positiva. O tumor foi classificado como leucemia mielomonocítica aguda pela massiva proliferação de células neoplásicas compatíveis com a série monocítica e neutrofílica na medula óssea, igualmente em múltiplos órgãos e a relativa imaturidade celular e predominância de blastos na medula óssea.

Palavras-chave: canino, leucemia mielomonocítica aguda histopatologia, imunoistoquímica.

\section{SUMMARY}

Acute myelomonocytic leukemia is described in a 4year-old female dog. During a two month period it presented anorexia, lethargy and progressive wasting. Laboratory results showed severe anemia and acute renal impairment. An ultrassonographic examination revealed a mesogastric mass. Once the dog did not respond to treatment it was euthanatiized. Macroscopically, deep pallor of mucous membranes, poor body condition and dehydration were detected. Some lymph nodes were swollen and tumoral nodules were observed in the liver, pancreas, regional lymph nodes, spleen and duodenum. The microscopic lesion consisted of neoplastic infiltration of the bone marrow, spleen, liver and lymph nodes. The cells were blastic myeloid cells with scant cytoplasm, round or segmented nucleus, prominent nucleolus and diffuse chromatin pattern. Immunohistochemical stains for NP57 were positive. The tumor was classified as acute myelomonocytic leukemia because of the morphology of the neoplastic cells and the predominance of blastic cells in the bone marrow.

Key words: dog, acute myelomonocytic leukemia, histopathology, immunohistochemistry.

\section{INTRODUÇÃO}

A leucemia mielomonocítica aguda é uma doença considerada como neoplasia de células clonais pouco diferenciadas, derivadas de dois sistemas, o monocítico e o neutrofílico, que possuem uma célula tronco em comum na medula óssea (unidade formadora de colônia monócito-granulócito). Se o nível de maturação é interrompido, ocorre a proliferação clonal (CHRISTOPHER et al., 1986, VALLI, 1993). As leucemias podem ser classificadas pela relativa maturidade da célula dominante e não fazem relação quanto à duração da doença. Se a célula dominante é relativamente madura e a medula não é constituída predominantemente por blastos, a desordem é classificada como crônica, ao passo que a neoplasia mieloproliferativa aguda envolve células imaturas e a medula óssea é constiuída predominantemente por blastos (EVANS \& GORMAN, 1987; PUCHEU-HASTON et al., 1995). Essa leucemia é classificada como M4, de acordo com a classificação das leucemias agudas proposta pelo Grupo de Estudo de Leucemia Animal da Sociedade Americana de Patologia Clínica Veterinária (GRAVES et al.,

\footnotetext{
${ }^{1}$ Médico Veterinário, Aluno do programa de Pós-graduação em Medicina Veterinária, Área de Concentração em Patologia Veterinária, Universidade Federal de Santa Maria (UFSM).

${ }^{2}$ Aluno de graduação em Medicina Veterinária, UFSM.

${ }^{3}$ Médico Veterinário, Professor Titular de Patologia, UFSM, 97105-900, Santa Maria, RS. E-mail: dlgraca@lince.hcv.ufsm.br Recebido para publicação em 18.10.99. Aprovado em 08.03.00
} 
1997). Ela é considerada rara nos animais domésticos e é relatada no cão com ocorrência menor de $1 \%$ de todas as leucemias (RAGAN et al., 1976; CHRISTOPHER et al., 1986; GRAVES et al., 1997).

A presença de elevado número de células neoplásicas circulantes não é sempre observada (COUTO, 1985; GRINDEM, 1985; CHRISTOPHER et al., 1986; MOULTON \& HARVEY, 1990). A história e sinais clínicos são de súbita anorexia e perda de peso progressiva, letargia, anemia, dispnéia e febre persistente. Anormalidades físicas incluem aumento de volume dos linfonodos cervicais, às vezes linfadenopatia generalizada, esplenomegalia e palidez das mucosas. O curso clínico é de 4 a 6 semanas (GRINDEM et al., 1985; COUTO, 1985). Achados macroscópicos incluem hepatoesplenomegalia, linfadenopatia e palidez da medula óssea. Estes estão associados com infiltração neoplásica na polpa vermelha do baço, sinusóides e áreas portais do fígado, sinusóides subcapsulares dos linfonodos, parênquima da medula óssea e estruturas vasculares dos órgãos (GRINDEM et al.,1985). Como diagnóstico final, além da histopatologia convencional, pode-se utilizar outras técnicas para classificação da linhagem celular das leucemias: a imunoistoquímica, baseada no uso de anticorpos precisamente selecionados para identificar antígenos teciduais ou celulares através da ligação de um anticorpo específico a um antígeno particular (MILLS, 1992; LI \& YAM, 1992) e o método citoquímico enzimático que classifica as células através de colorações com marcadores enzimáticos. Em muitos casos, os blastos são pouco diferenciados e colorações citoquímicas são úteis para identificar as características morfológicas das células (ROHRIG, 1983; RAGAN et al., 1976).

\section{RELATO DO CASO}

Uma cadela de quatro anos apresentou, no período de dois meses, anorexia, emagrecimento progressivo, letargia e anemia intensa. Realizou-se transfusão sangüínea com melhora transitória no quadro clínico. Os exames laboratoriais constataram anemia intensa, insuficiência renal aguda e, na ultrasonografia, observou-se massa na região mesogástrica. Após tentativa de tratamento clínico sem resposta, optou-se pela eutanásia. $\mathrm{O}$ animal foi necropsiado e fragmentos de massas tumorais do fígado, baço, linfonodos adjacentes e pré-esternais e de vários outros tecidos foram colhidos, fixados em formol $10 \%$ e processados rotineiramente para histopatologia. Cortes corados pela Hematoxilina \& Eosina foram examinados por microscopia ótica.
Um corte histológico da medula óssea foi selecionado para imunoistoquímica. A recuperação do antígeno foi feita com EDTA e foi utilizado como marcador o anticorpo monoclonal NP57 ${ }^{\mathrm{a}}$ (marcador de neutrófilos e seus precursores) na titulação de 1:100.

\section{RESULTADOS}

Os exames laboratoriais revelaram aumento da creatinina sérica $(2,25 \mathrm{mg} / \mathrm{dl})$ e da uréia $(77 \mathrm{mg} / \mathrm{dl})$, indicando um quadro clínico de insufiência renal. O hematócrito teve uma variação de 15 a $22 \%$ e a contagem de eritrócitos foi de 2,6 milhões $/ \mathrm{mm}^{3}$, caracterizando o estado anêmico do animal.

Macroscopicamente, observaram-se acentuada palidez das mucosas, pobre estado nutricional e desidratação. Os linfonodos pré-esternais estavam aumentados até três vezes o seu tamanho normal e, ao corte, estavam brancos homogêneos com perda da diferenciação córtex-medular. Nos lobos esquerdos do fígado, havia múltiplos nódulos tumorais branco-amarelados variando de 0,5 a $2 \mathrm{~cm}$ de diâmetro e centro deprimido (Figura 1), em alguns locais coalesciam formando nódulos maiores, um deles no lobo caudal atingindo $8 \mathrm{~cm}$ de diâmetro. A superfície externa desses nódulos estava aderida ao diafragma em quase toda a sua extensão. $\mathrm{Na}$ parte inicial do duodeno, havia uma grande massa $(15 \mathrm{~cm}$ de diâmetro) envolvendo os linfonodos locais e pâncreas onde as alças intestinais estavam aderidas. Ao corte, essas massas eram amareladas com pequenas áreas cinzentas se fragmentando (necrose). As tumorações eram firmes e possuíam estruturas que lembravam ductos de tamanhos variados e repletos de conteúdo friável pardo-escuro. Os linfonodos abdominais estavam aumentados duas vezes o tamanho normal e envolviam o baço. $\mathrm{O}$ rim direito estava aumentado

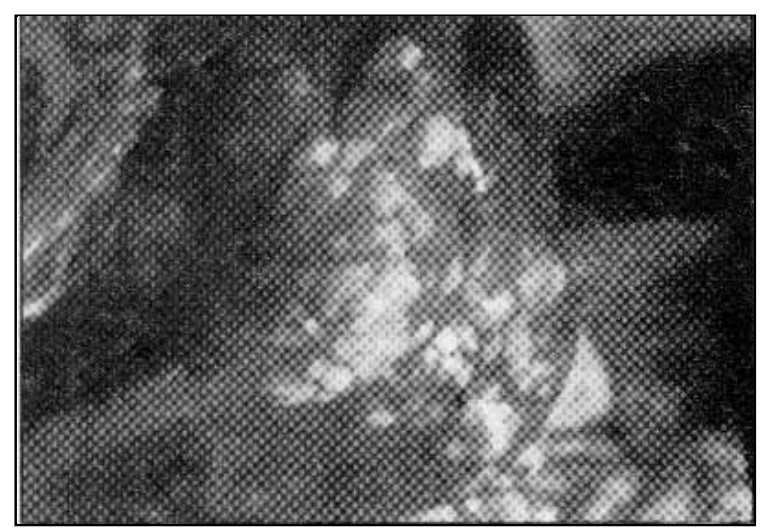

Figura 1 - Fígado: nódulos de infiltração tumoral. 
duas vezes o tamanho normal e a superfície cortical estava bastante amarelada. Ao corte, a pelve e o ureter estavam dilatados.

Microscopicamente, havia infiltração tumoral na medula óssea, baço, linfonodos e fígado. A medula óssea estava hiperplásica e preenchida por células blásticas com pouco citoplasma, núcleo redondo ou chanfrado, nucléolo proeminente e cromatina fina. Havia, também, moderada quantidade de neutrófilos. Megacariócitos estavam em menor número e tamanho (Figura 2). Nos linfonodos, observaram-se o mesmo infiltrado tumoral descrito na medula e trombose por êmbolos tumorais. No baço, havia proliferação de células hematopoéticas pouco diferenciadas e alguns megacariócitos reativos. No fígado, havia grande infiltração de células blásticas com morfologia semelhante à descrita na medula óssea desfazendo a arquitetura normal, com necrose e perda de hepatócitos. Em algumas áreas, observaram-se acúmulos de neutrófilos circundados por finas bandas de tecido conjuntivo. A massa tumoral maior era constituída por células redondas, bastante eosinofílicas, citoplasma granular, uniformes, com $15 \mu \mathrm{m}$ de diâmetro, formando acúmulos separados por septos e bandas de tecido conjuntivo. Havia, também, numerosas células com pigmento marronamarelado. No rim, observaram-se atrofia glomerular e dilatação tubular com cilindros hialinos na luz. Cristais semelhantes a oxalatos na luz tubular, bem como sais de cálcio de distribuição aleatória também foram observados. Detectou-se proliferação de células neoplásicas no interstício, comprimindo e/ou substituíndo túbulos. Imunoistoquímica da medula óssea, utilizando o anticorpo NP57, foi positiva.

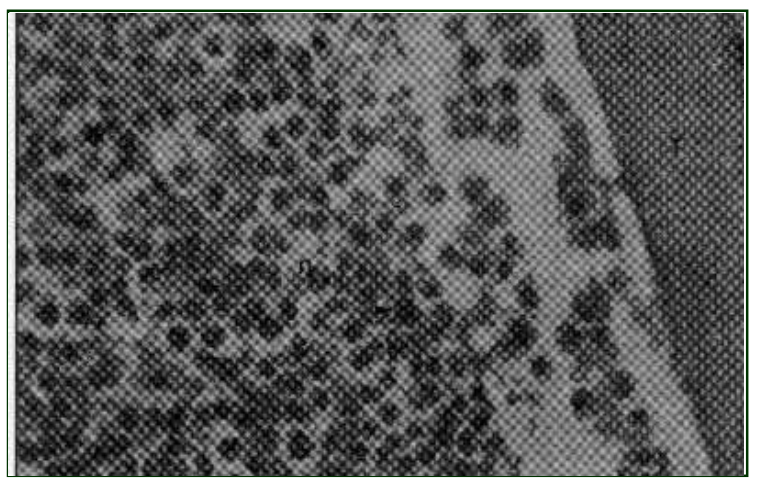

Figura 2 - Leucemia mielomonocítica aguda. Medula óssea: densamente preenchida por células blásticas com pouco citoplasma, núcleo redondo ou chanfrado, nucléolo proeminente e cromatina fina, moderada quantidade de neutrófilos e alguns megacariócitos T: trabécula óssea; n: neutrófilos; ( $>$ ) células blásticas. Coloração de H e E. 1600X.

\section{DISCUSSÃO}

A história clínica, achados de necropsia e a massiva proliferação de células neoplásicas compatíveis com a série monocítica e neutrofílica na medula óssea, e igualmente em múltiplos órgãos, além da relativa imaturidade celular e predominância de blastos na medula óssea, são indicativos de leucemia mielomonocítica aguda. A imunoistoquímica da medula óssea permitiu chegar ao diagnóstico da origem mielomonocítica das células. Determinou-se como aguda baseado na relativa imaturidade celular e predominância de blastos na medula óssea.

O marcador utilizado na imunoistoquímica foi específico para os neutrófilos e seus precursores. A escolha desse marcador baseou-se na origem comum dos granulócitos e monócitos (EVANS \& GORMAN, 1987) sendo que, o anticorpo marca não apenas o neutrófilo, mas também seus precursores.

O referido animal apresentava pronunciado aumento dos linfonodos pré-esternais e, clinicamente, poder-se-ia-se suspeitar de linfossarcoma, e não foi encontrada explicação para o quadro de anemia, sendo o animal eutanasiado sem diagnóstico clínico. A observação do aumento dos linfonodos superficiais pode induzir a um diagnóstico de linfossarcoma; que pode, ocasionalmente, estar associado à leucemia mielóide aguda. Nesse caso, o infiltrado de células tumorais nos linfonodos era morfologicamente compatível com o observado nos demais órgãos. A classificação é importante para o prognóstico e tratamento do animal. O prognóstico para a M4 é extremamente pobre e o tratamento não é recomendado (GRAVES et al.1997).

Nesse caso, não foram detectadas células tumorais na circulação. EVANS \& GORMAN (1987) afirmam que nas leucemias, células anormais podem não estar necessariamente presentes no sangue periférico, como já apontado em alguns relatos, e a quantidade de células brancas no sangue pode não estar aumentada na circulação. Às vezes, na medula óssea, pode haver predominância por células anormais, mas não há supressão da produção celular normal ou a liberação de células neoplásicas na circulação. Essa condição tem sido chamada de leucemia latente, embora o termo não seja inteiramente apropriado, porque, em alguns casos, a doença pode progredir rapidamente.

A etiologia permanece indefinida nesse caso, como em outros relatos (EVANS \& GORMAN, 1987). Sugere-se a etiologia viral ou suscetibilidade genética através de evidências epidemiológicas da doença. Em gatos, a doença foi 
reproduzida experimentalmente com o vírus da leucemia felina. No homem, radiação e uma variedade de produtos químicos, incluindo solventes e drogas, têm sido implicados na etiologia (EVANS \& GORMAN, 1987).

Esse relato objetiva, principalmente, ressaltar a ocorrência da doença e a importância do diagnóstico. Na observação de sinais clínicos aparentemente semelhantes aos da leucemia e sem indicação de outras possíveis causas, deve-se procurar fazer os exames necessários. $\mathrm{O}$ indicado é procurar pelas células leucêmicas no sangue mas, neste caso e em outros relatos, nem sempre as células estão presentes na circulação, sendo necessário exame do aspirado da medula óssea. MOULTON \& HARVEY (1990) descrevem que, no exame, a medula óssea apresenta-se hipercelular, e morfologia anormal pode ser observada em algumas ou todas as linhagens presentes no tecido.

\section{FONTE DE AQUISIÇÃO}

a - Dako Corporation Santa Barbara, CA. 93103. U.S.A.

\section{REFERÊNCIAS BIBLIOGRÁFICAS}

CHRISTOPHER, M.M., METZ, A.L., KLAUSNER, J., et al. Acute myelomonocytic leukemia with neurologic manifestations in the dog. Vet Pathol, v.23, p.140-147, 1986.

COUTO, C.G. Clinicopathologic aspects of acute leukemias in the dog. J Am Vet Med Assoc, v.186, p.681-685. 1985.

EVANS, R.J., GORMAN, N.T. Myeloproliferative disease in the dog and cat: Definition, etiology and classification. Vet Rec, v.121, p.437-443, 1987.
GRAVES, T.K., SWENSON, C.L., SCOTT, A. A potentially misleading presentation and course of acute myelomonocytic leukemia in a dog. J Am Anim Hosp Assoc, v.33, p.37-41, 1997.

GRINDEM, C.B., STEVENS, J.B., PERMAN, V. Morphological classification and clinical and pathological characteristics of spontaneous leukemia in 17 dogs. J Am Anim Hosp Assoc, v.21, p.219. 1985

LI, CHIN - YANG, YAM, L.T. Cytochemical, histochemical, and immunohistochemical analysis of the bone marrow. In: KNOWELS, D. M. Neoplastic hematopathology. Baltimore: Willians \& Wilkins, 1992. Cap.36. p.1097-1134.

MILLS. B. Immunohistochemistry. In: PROPHET, E.B., MILLS, B., ARRINGTON, J.B., SOBIN, L.H. Laboratory methods in histotechnology. Washington : American registry of pathology. 1992. Cap.23. p.247-263.

MOULTON, J.E., HARVEY, J.W. Tumors of the lymphoid and hematopoietic tissues. In: MOULTON, J. E. (ed.). Tumors in domestic animals. 3.ed. Berkeley : University of California, 1990. Cap.9. p.231-296.

PUCHEU-HASTON, M.C., CAMUS, A., TABOADA, J., et al. Megakaryoblastic leukemia in a dog. J Am Vet Med Assoc, v.207, n.2, p.194-196, 1995.

RAGAN, H.A., HACKETT, P.L., DAGLE, G.E. Acute myelomonocytic leukemia manifested as myelophthisic anemia in a Dog. J Am Vet Med Assoc, v.169, n.4, p.421425, 1976.

ROHRIG, K.E. Acute myelomonocytic leukemia in a dog. J Am Vet Med Assoc, v.182, n.1, p.137-141, 1983.

VALLI, V.E.O. The hematopoietic system. In: JUBB, K.V.F., KENNEDY, P.C., PALMER, N. (eds). Pathology of domestic animals. 4. ed. San Diego : Academic, 1993. Cap.2. p.101-265.

Ciência Rural, v. 30, n. 5, 2000. 